\title{
The impact of flood in 2018 on the socio- economic conditions of the dairy farmers in Pariyaram panchayat of Thrissur district of Kerala
}

M. Saravanan', A. Prasad², Joseph Mathew ${ }^{3}$, Justin Davis ${ }^{2}$ and V.L. Gleeja ${ }^{4}$ Department of Livestock Production Management, College of Veterinary and Animal Sciences, Mannuthy, Thrissur - 680651. Kerala Veterinary and Animal Sciences University, Kerala, India.

Citation: Saravanan. M , Prasad, A. , Joseph Mathew, Justin Davis and Gleeja V.L. 2021. The impact of flood in 2018 on the socio-economic conditions of the dairy farmers in Pariyaram panchayat of Thrissur district of Kerala. J. Vet. Anim. Sci. 52(3): $272-276$.

DOI: https://doi.org/10.51966/jvas.2021.52.3.272-276

Received:22.01.2021

Accepted: 29.03.2021

Published: 30.09 .2021

\section{Abstract}

Climate change poses existential threat on all forms of life on earth. Flood is one of the major fallout of it. Tropical humid zones experiences worst form of rain related disasters in the recent times. Kerala, a tropical humid state of India experienced one of the most destructive flood events of the century during August 2018. It had heavy impact on every sector including animal husbandry. Based on this event, a study was conducted to assess the impact of flood in 2018 on Livestock Farming System of Pariyaram Panchayat in Thrissur district of Kerala. The entire Panchayat was delineated into affected and unaffected wards and detailed survey on faming system and socio economic profile of the flood affected area was conducted. Pre and post flood livestock system of the flood affected area differed significantly regarding herd strength, milk production and feeding pattern. Livelihood of farmers who were depending on the agriculture and livestock rearing for their survival suffered due to the event, suggesting need for better preparedness.

Keywords: Climate change, livestock sector, socio-economic impact of flood

Climate change threatens all the living features on earth. According to intergovernmental panel on climate change, earth has started suffering the consequences of $1^{\circ} \mathrm{C}$ increase in average global temperature, and due to disruption of the oceanic current leading to frequent episodes of extreme weather, rising sea level and waning polar ice caps. One of the extreme weather events which occur during climate change is a flood. Floods occurs whenever there is excessive runoff of water in any natural drainage channels (Chaw, 1956). During August 2018, Kerala experienced one of the most destructive floods of the century. This happened due to the excessive rainfall in

${ }^{*}$ Part of M.V.Sc thesis submitted by the first author to Kerala Veterinary and Animal Sciences University, Pookode, Wayanad, Kerala.

1. M.V.Sc Scholar and corresponding author email: sarvanvet@gmail.com, ph.: 6380440701

2. Assistant professor, Department of Livestock Production Management

3. Professor and Head, Department of Livestock Production Management

4. Assistant professor and Head (I/C), Department of Statistics

Copyright: ( 2021 Saravanan et al. This is an open access article distributed under the terms of the Creative Commons Attribution 4.0 International License (http://creativecommons.org/licenses/by/4.0/), which permits unrestricted use, distribution, and reproduction in any medium, provided the original author and source are credited. 
a short span of time, geographical peculiarity of the land pattern and lack of proper drainage system. Pariyaram Panchayat is located in Thrissur district which was affected by both flood and landslides due to its topographic pattern. Majority of the inhabitants were involved in agriculture and animal husbandry. The present study reveals the socio economic profile and livestock farming practices of flood affected farmers in Pariyaram Panchayat in Thrissur district of Kerala. This would help in future for better adoption and management during such calamities.

\section{Materials and methods}

\section{Location of study}

Pariyaram panchayat is located at $10.3200^{\circ} \mathrm{N}, 76.3705^{\circ} \mathrm{E}$ in Thrissur district of Kerala near Chalakkudy taluk with $16.8 \mathrm{~km}^{2}$ area and with population of 31195 (2011 census). Due to its topographic peculiarity, the panchayat was affected by landslides as well as floods during 2018. Out of 15 wards, Peelarmuzhi ward was not affected (control area) remaining 14 wards were affected at varying severity (study area) was selected for this study.

\section{Methodology}

For primary data, survey was conducted among 300 livestock farmers of Panchayat to assess the socioeconomic profile and livestock farming systems of flood affected area. Secondary data was collected from the journals, newspaper and grama panchayat office. Primary and secondary data were analyzed both quantitatively and qualitatively. Microsoft Excel was used for data processing and data analysis.

\section{Results and discussion}

\section{Socio economic profile of flood affected people}

Educational status of the people of the study area (Fig. 7) i.e. the Pariyaram panchayat was found to be as follows. Most of the respondents surveyed had an educational level of higher secondary level (38 per cent), followed by high school (25.33 per cent), primary (18.6 per cent), graduate (15.4 per cent) and post graduate (2.67 per cent). Das and Dey (2011), reported that among the flood affected people from Barak valley, the majority had education up to higher secondary level of education, so the study areas were similar in terms of education status. Agriculture (39.61 per cent) was the primary and major occupation of the people of the present survey (Fig. 2) and a similar study by Prajisha (2019) in Chathanmangalam panchayat also had reported that majority of the respondents from flood affected area were involved in agricultural activities. So, we have to consider vulnerability of farming community as a major aspect in preparedness regime.

Survey revealed that majority of the people lived in nuclear family system (61.9 per cent) in the study area. This finding was in contrast with that of Kumar et al. (2013) who reported that majority of farmers in Gujarat were living in joint families (70.83 per cent) and (29.17 per cent) belonged to nuclear families, that will help for managing farming activities. This is because the current social reality of Kerala forces people to have nuclear family structure which at the same time has a lot of bearing on the lack of resilience of the family to counteract and survive calamities.

Majority of the respondents had an annual income (Fig. 6) of less than (Rs) 50,000 (52.63 per cent), 27.04 per cent had an income between 50,000 to $4,00,000$ and 20.33 per cent was above $4,00,000$. This finding was in accordance with Pradeep and Rajesh (2020) who reported that majority of the flood affected households were below the poverty line (52 per cent) in Pothukallu panchayat. Regarding land holding capacity, most of the people had very small land holding with less than five cents (63.28 per cent), 35.09 per cent had between 5 to 10 cents and 1.95 per cent had above 10 cents. This was in accordance with Rathod et al. (2012) who observed that majority of the farmers studied had a landholding less than five cents for their crop cultivation. This may be due to the topographic location and thus it reduces the land capacity and most of them were below poverty line that makes them to have less land for farming. 


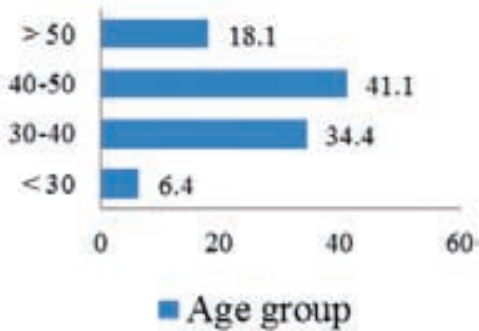

Fig. 1. Age

= Pre flood $=$ Post flood

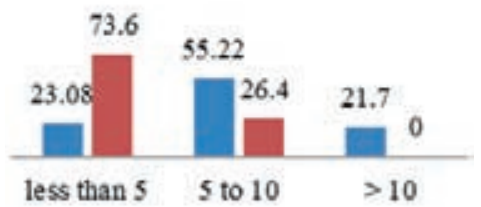

Fig. 3. Herd strength

(No. of animals)

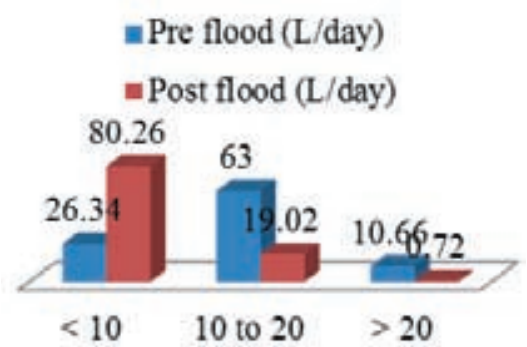

Fig. 5. Milk produced

Fig. 9. Water source
Well

water

- Bore

water

Others

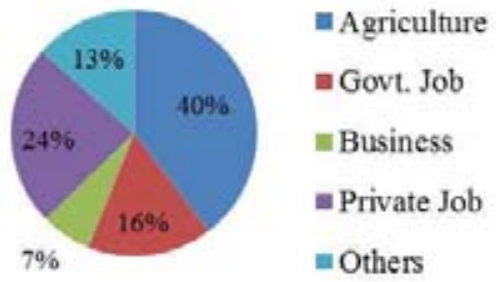

Fig. 2. Occupation

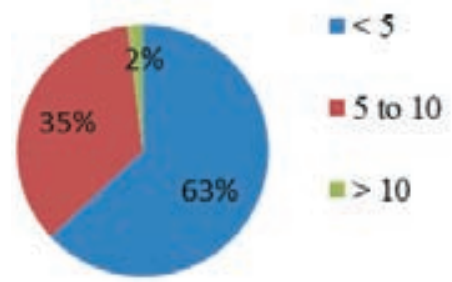

Fig. 4. Land Holding (Cents)

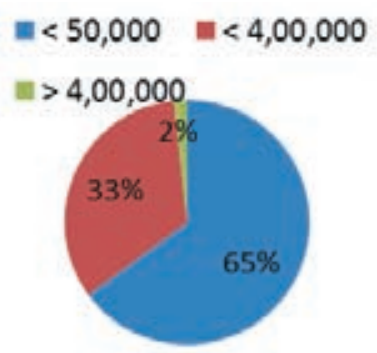

Fig. 6. Annual income (Rs)

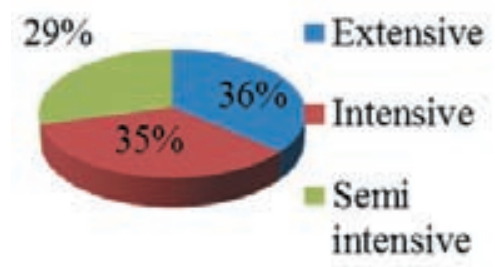

Fig. 8. Animal rearing
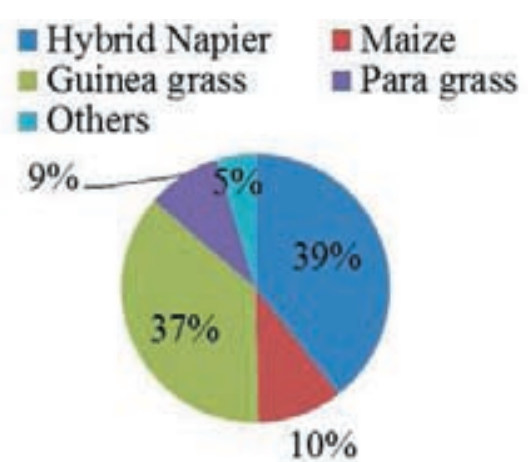

Fig. 10. Fodder crops cultivated 
Nearly 93.33 per cent of respondents were directly affected by flood. Rashid and Paul (1987) reported that one third of our country's population was directly affected by flood because of the plain region which gets easily washed off. Regarding the housing pattern, 64.85 per cent of the respondents were having concrete house, followed by tiled (18.06 per cent), and thatched (17.09 per cent). This finding was similar with Pradeep and Rajesh (2020) who revealed that flood affected people from Pothukallu Panchayat had 72 per cent of concrete house, 24 per cent had tiled houses and remaining had thatched houses.

\section{Herd details of livestock farmers}

Majority of livestock farmers in Pariyaram had an experience of less than five years (52.73 per cent), followed by five to ten years (37.4 per cent) and more than 10 years (9.87 per cent). This finding was in contrast to that of Rajadurai et al. (2018) who reported that majority of livestock farmers had an experience of more than 10 years in rural area where majority of people were involved in animal rearing for their livelihood. There is a shift in the demographic profile of people interested in livestock and in Kerala with more youngsters taking up livestock as a business and at the same time there is a large-scale withdrawal of older people from livestock.

The survey also revealed that majority of farmers had around five to ten animals (55.22 per cent) in pre flood period (Fig. 3). The number of animal units reduced and in post flood situation revealed by the fact that majority had less than five animals (73.16 per cent) post flood. This finding was similar with Kad et al. (2014) who studied on the post flood impact in Pune district revealed that majority of farmers had less than eight animals in herd (62 per cent) and also in post flood condition many animals were lost due to drowning and lack of feed for their nutritional support. This was similar with Chauhan and Ghosh (2014) who had reported that majority of livestock were lost after flood due to feed scarcity and wash off in flood water.

Regarding milk production (Fig. 5) majority of farmers produced less than $10 \mathrm{~L} / \mathrm{d}$
(80.26 per cent) after flood and in pre flood condition majority produced around 10 to $20 \mathrm{~L}$ day (63 per cent). This was similar with George (2016) who reported that majority of farmers in Kerala produced milk between 10 to $20 \mathrm{~L} / \mathrm{d}$ from small and medium sized farms. This finding was in accordance with Haile et al. (2013) studied 60 per cent of households had negative yield in milk production by reducing two liters per day after 2007.

\section{Feeds and feeding management of livestock farmers}

Regarding feeding pattern, majority of farmers fed concentrate to dairy cows at rates between 5 to $10 \mathrm{~kg} /$ day (54.68 per cent) and drastically changed after flood, were they fed with less than five $\mathrm{kg} /$ day (50.33 per cent). Regarding feeding of roughages, majority of respondents fed less than five $\mathrm{kg} /$ day (46.66 per cent). This finding was similar with George (2016) who studied that majority of the dairy farmers provided less than $10 \mathrm{~kg} /$ day to their animals in Kerala.

Mostly, people depended on well water as a water source (Fig. 9) to their livestock (59 per cent), followed by bore well (22 per cent) and others (19 per cent). This finding was similar with Riche (2017) who studied that people in Kerala depended on well water for livestock use and human use. So, keeping well water uncontaminated during the time of flood is a major strategy in the climate change adaptation plan for ensuring safe water.

\section{Fodder cultivation Practices of livestock farmers}

Major fodder varieties cultivated (Fig.10) by the farmers were hybrid Napier (39.34 per cent), followed by Guinea grass (36.37 per cent), Maize (10.33 per cent), para grass (nine per cent) and other varieties (4.66 per cent). This was in accordance with Rahman (2014) who reported that 40 per cent of people cultivated hybrid Napier for their livestock for feeding. In study area nearly 61 per cent of cultivable land was flooded which was similar with Prajisha (2019) reported that 57 per cent of crops which were cultivated in plantain region were lost in flood that occurred in Kerala in 
2018.

\section{Conclusion}

Flood is a major fallout of climate change. The present study conducted in a flood affected area reiterates the vulnerability of faming system to flood. Keeping well water uncontaminated during the time of flood is a major strategy in the climate change adaptation plan for ensuring safe water. Study warns long term negative impact on feed, fodder and milk production in affected area. So, we have to consider the vulnerability of farming community as a major aspect in the total preparedness regime.

\section{Conflict of interest}

Certified that there is no conflict of interest to be declared in the present work.

\section{References}

Chauhan, D. S. and Ghosh, N. 2014. Impact of climate change on livestock production: A review. J. Anim. Res. 2: 223-239.

Chaw, V. T. 1956. "A General Formula for Hydrologic Frequency Analysis". Trans. Amer. Geophy. Union. 32: 231-237.

Das, P. and Dey, N. B. 2011. Socio-economic vulnerability in a flood affected village of Barak valley, Assam, India. Asia Pacif. J. Social Sci. 2: 110-123.

George, S. 2016. Economics of Dairy farming systems in Kerala. Department of Livestock Production Management, College of Veterinary and Animal Sciences, Mannuthy, Thrissur. (M.V.Sc Thesis)

Haile, A. T., Kusters, K., and Wagesho, N. 2013. Loss and damage from flooding in the Gambela region, Ethiopia. Int. J. Global Warming. 4: 483

Kad, S. V., Kale, R. B., Vairagar, V. G. and
Wadkar, S. K. 2014. Innovativeness, Utilization Pattern and Scientific Production Technology of Fodder Crops in Maharashtra:An Exploratory Research from Dairy Farmers' Perspective. Indian J. Dairy Sci. 67: 359-364

Kumar, V., Prajapati, R. S., Ghintala, A. and Singh, K. 2013. Source and channels of agriculture information used by the beneficiary farmers of NAIP-III. Gujarat J. Ext. Educ. 24: 14-67.

Pradeep, M. B. and Rajesh, E. 2019. The impact of flood on the socio-economic life's of the people in Pothukallu panchayat with special reference to Kavalappara at Malappuram districts, Kerala. Int. J. Econ. Business rev. 7: 32-37.

Prajisha P. 2019. Impact of flood in Kerala: A case study in Chathamangalam panchayat, ISSN: 2455-8834, Volume: 04, Issue: 04 "April 2019. Int. J. Soc. Sci. Econ. Res. pp. 45-48.

Rahman, S. U. 2014. Impacts of flood on the lives and livelihoods of people in Bangladesh: A case study of a village in Manikganj district (Doctoral dissertation, BRAC University).

Rajadurai, A., Rajaganapathy, V., Ganeshan, R., Ponnuvel, P., Natchimuthu, K. and Sreekumar, D. 2018. Socio-economic profile of the dairy farmers in Puducherry. Int. J. Adv. Res. Biol. Sci. 5: 91-95.

Rasid, H. and Paul, B. K. 1987. Flood problems in Bangladesh: is there an indigenous solution. Environ. Mgmt. 2: 155-173.

Rathod, P. K., Landge, S., Nikam, T. R. and Vajreshwari, S. 2012. Socio-personal profile and constraints of dairy farmers, Karnataka. J. Agric. Sci. 24: 619-621.

Riche, E. L., Vander Zag, A. C., Burt, S., Lapen, D. R. and Gordon, R. 2017. Water Use and Conservation on a Free-Stall Dairy Farm. Water. 9: 977. 